This item was submitted to Loughborough's Research Repository by the author.

Items in Figshare are protected by copyright, with all rights reserved, unless otherwise indicated.

\title{
When assistance is not given: disaffiliative responses to therapeutic community clients' implicit requests
}

PLEASE CITE THE PUBLISHED VERSION

http://www.palgrave.com/

\section{PUBLISHER}

Palgrave Macmillan

VERSION

AM (Accepted Manuscript)

\section{PUBLISHER STATEMENT}

This work is made available according to the conditions of the Creative Commons Attribution-NonCommercialNoDerivatives 4.0 International (CC BY-NC-ND 4.0) licence. Full details of this licence are available at: https://creativecommons.org/licenses/by-nc-nd/4.0/

\section{LICENCE}

CC BY-NC-ND 4.0

\section{REPOSITORY RECORD}

Pino, Marco. 2019. "When Assistance Is Not Given: Disaffiliative Responses to Therapeutic Community Clients' Implicit Requests”. figshare. https://hdl.handle.net/2134/19636. 


\title{
When Assistance Is Not Given: Disaffiliative Responses to Therapeutic Community Clients' Implicit Requests
}

\author{
Marco Pino ${ }^{1}$
}

\begin{abstract}
In this chapter I examine interactions between the clients and the staff members of a Therapeutic Community (TC). The TC clients sometimes use expressions of need ("I need X") and desire ("I would like X") to convey implicit requests for assistance. Analysis illustrates that with these expressions the clients provide the staff members with an opportunity to offer assistance, instead of overtly demanding it. This can put the TC staff members in a delicate position when, for several reasons, they may be reluctant to assist the clients in the achievement of particular goals (such as renewing a driver's license, buying a car, etc.). The staff members sometimes deal with this problem by disaffiliating with the clients' projects to achieve particular outcomes (e.g. renewing a driver's license) on the basis that the clients (allegedly) lack entitlement to those outcomes. This practice enables the staff members to convey that assistance will not be provided, without saying it in so many words.
\end{abstract}

Pino, M. (2016). When assistance is not given: disaffiliative responses to Therapeutic Community clients' implicit requests. In M. O’Reilly \& J. Parker (Eds.), The Palgrave Handbook of Adult Mental Health, pp. 674-693. Palgrave Macmillan.

${ }^{1}$ Department of Social Sciences - Loughborough University, UK.

t: +44 (0)1509 222544. Email: m.pino@1boro.ac.uk 


\section{Introduction}

Therapeutic Communities (TCs) are residential rehabilitation services for people with diagnoses of mental illness (Campling, 2001). TCs are programmatically removed from hospitals, they are set up in home-like settings, and they host a relatively small number of clients. Clients are expected to be actively involved in the practical management of the house by sharing responsibilities with the staff (such as cooking, cleaning, and the like). The hierarchical demarcation between staff and clients is expected to be reduced compared to more traditional mental health institutions (Campling, 2001). TC clients also enjoy more freedom than in more traditional mental health institutions (e.g., hospital wards), particularly by being allowed to exit the TC unaccompanied, having a job, taking part in free-time activities, and entertaining relationships with people outside the TC. This is unlike psychiatric hospitals, particularly forensic-care hospitals, where patients have little free movement (Bone \& Marchant, Chapter 23, this volume; Dobbinson, Chapter 22, this volume)

Although in TCs the hierarchical separation between staff and clients is reduced, it is not completely levelled out. Previous research has shown how TC staff members' conversational practices implement the institutionally relevant task of encouraging TC clients' adherence to expectations about appropriate conduct (Mortari \& Pino, 2014). In this chapter, I examine another way that the asymmetrical distribution of prerogatives between TC staff and clients is oriented to and implemented in conversational interactions. By examining group meetings recorded in an Italian TC, I focus on cases where the TC clients bring their needs and desires to the attention of the TC staff members and how, by doing this, the clients give the staff members opportunities to offer assistance in fulfilling those needs and desires. I then focus on a practice that the TC staff members use to disaffiliate with (i.e. to show that they do not endorse; Stivers, 2008) the clients' project to obtain some goods or services: treating the clients as lacking entitlement to those goods or services.

\section{Data and method}

The data for this study consist of four group meetings (each lasting approximately one hour) audio-recorded in a TC in Italy in 2008. The TC was residential and could host a maximum12 clients. During the data collection period, the majority of clients were diagnosed with schizophrenia. The meetings took place on a weekly basis and were attended by the TC clients, a nurse (Massimo), an educator (Barbara) and occasionally other staff members (healthcare assistants).

In the recorded meetings the participants engage in a range of activities, including sharing recent events experienced by the clients (and associated thoughts and feelings), reviewing the clients' performance (e.g., in specific tasks and responsibilities they had been given), planning for future events (e.g., a seaside vacation), and also 
small talk. Clients' requests emerge in all these activities. The participants gave written consent to publish the data. All names used in this chapter are pseudonyms.

The method used in this study is Conversation Analysis (CA) (Sidnell \& Stivers, 2013). For this study, I collected all the sequences where the clients more or less explicitly issue a request. The original conversations are partly in Italian and partly in a local dialect; I transcribed them following the conventions commonly used in CA (Hepburn \& Bolden, 2013) and illustrated in Table 1.3. In addition, I used the period (“.") for unit-final falling intonation, the question mark ("?") for rising intonation, the comma (",") for slightly rising ("continuing') intonation, the underscore ("_") for level intonation and the inverted question mark (" $"$ ") for a pitch rise that is stronger than a comma (“,”) but weaker than a queston mark (“?”). The hashtag (“\#”) represents creaky voice and the tidle (" $\sim$ ") represents tremulous voice. In this chapter, the data are presented in a double line: original language and English idiomatic translation. In the next section, I present an overview of the clients' requests and the staff members' responses. Subsequently, I illustrate how the clients' descriptions and displays of need or desire can be understood as implicit requets. Then, I focus on the staff members' practice of treating the clients as lacking entitlement to the goods and services targeted by their implicit requests.

\section{TC clients' requests for goods and services}

Previous research has found that requests can be formulated by explicitly enunciating the type of action that the speaker is asking the recipient to perform. An example is the Can you do $X$ type of utterance (e.g., 'Can you come over in the morning?', Curl and Drew, 2008, p. 137, Extract 2, lines 5-6). This request format overtly conveys the expectation that the intended recipient performs an action. The TC clients use explicit request formats, either the imperative or, more commonly, the interrogative (e.g., 'Will you give me X' or 'Can I do X'; see Rossi, 2012) to request goods that the staff members ordinarily administrate and dispense (e.g., money and cigarettes) or permission to engage in activities that the staff members ordinarily authorise and supervise (e.g., group activities outside the TC). The staff members' responses either grant or deny the provision of what the clients requested, or they defer the decision to a subsequent time after the meeting. Through these responses, the staff members treat the clients' requests as actions that make relevant an accepting or a rejecting response (Schegloff, 2007), either now or at some other time.

In this chapter, I focus on cases where the clients issue requests less explicitly, by describing or displaying a need or a desire for something (e.g., through the $I$ need $X$ type of utterance; Couper-Khulen, 2014; Stevanovic, 2011). Through assertions and displays of need or desire, the clients do not overtly demand some goods and services; instead, they provide the staff members with an opportunity to offer assistance in obtaining them (Curl, 2006; Gill, 2005; Kendrick \& Drew 2014). Assertions of need 
and desire therefore have request implications, which are left to the staff members to infer and to act upon. The next section examines the conditions under which the participants treat expressions of need or desire as performing implicit requests.

\section{TC clients' expressions of need and desire as implicit requests}

Previous research has shown that the treatment of expressions of need and desire as implicit requests is contingent upon the participants' orientation to a speaker-recipient social relationship where the recipient has the ability to satisfy the speaker's needs or desires and where the recipient can be expected to be willing or obliged to do so (socalled benefactive relationship, Clayman \& Heritage, 2014; see also Stevanovic, 2011). The following example demonstrates that a client's assertion of desire can but need not be treated as an implicit request; different ways of treating the assertion (as a request or as different type of action) are linked to different understandings of the social relationship that exists between the clients and the staff members.

Before the start of Extract 1, Massimo (the TC nurse) has reported that the staff members suspect that Franco (a client) has not taken his medication for some time. Relevant for the understanding of this exchange is that the clients' pharmacological regimes are prescribed by psychiatrists who do not work in the TC. The TC staff members have a duty to administer the medication, but they cannot change prescriptions. In Extract 1, I reproduce only some parts of a lengthy exchange, which are relevant to the argument made here (for a more extended treatment of this episode, see Mortari \& Pino, 2014). In all the extracts, the letter preceding the participant's name stands for their role ( $\mathrm{S}$ for staff and $\mathrm{C}$ for client).

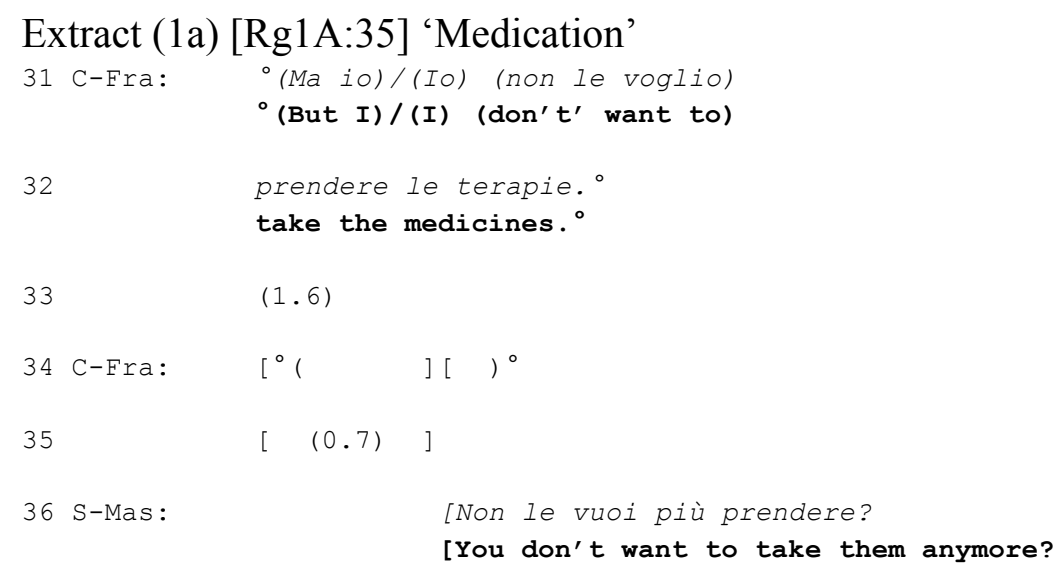

At lines 31-32 Franco states that he does not want to take some drugs he was prescribed. Being designed as an assertion of desire (in this case, a desire not to do something), this turn can be heard as an implicit request. However, staff member Massimo treats Franco's turn as providing information (line 36), not as making a request (Stevanovic, 2011). Later in the meeting (Extract 1b) it emerges that Franco's unwillingness to take 
the medication is treated as his own problem to solve, rather than a request that the staff do something about it (Barbara is another staff member):

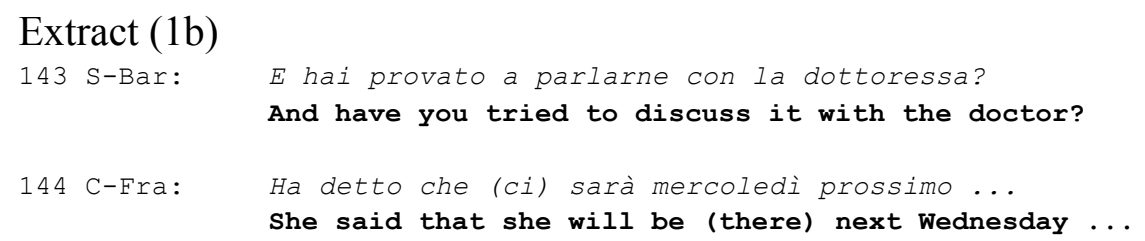

Barbara's turn at line 143 elects 'discussing it with the doctor' as an appropriate course of action for trying to sort out Franco's problem. The doctor (i.e. Franco's psychiatrist) is thereby treated as the appropriate recipient for a request to stop taking the medication. Barbara (who is an educator) does not treat herself or any other of the co-present TC staff members (i.e. a nurse, and two healthcare assistants) as having the prerogative to do something about Franco's problem. This suggests that a client's assertion of desire is not treated as an implicit request when its recipients (here, the staff members) treat themselves as lacking the ability to satisfy that desire. However, later in the meeting, it emerges that another client (Clara) may have heard Franco's assertion of desire as an implicit request and that she oriented to the possibility that the staff members have the power to grant that request.

Extract (1c)

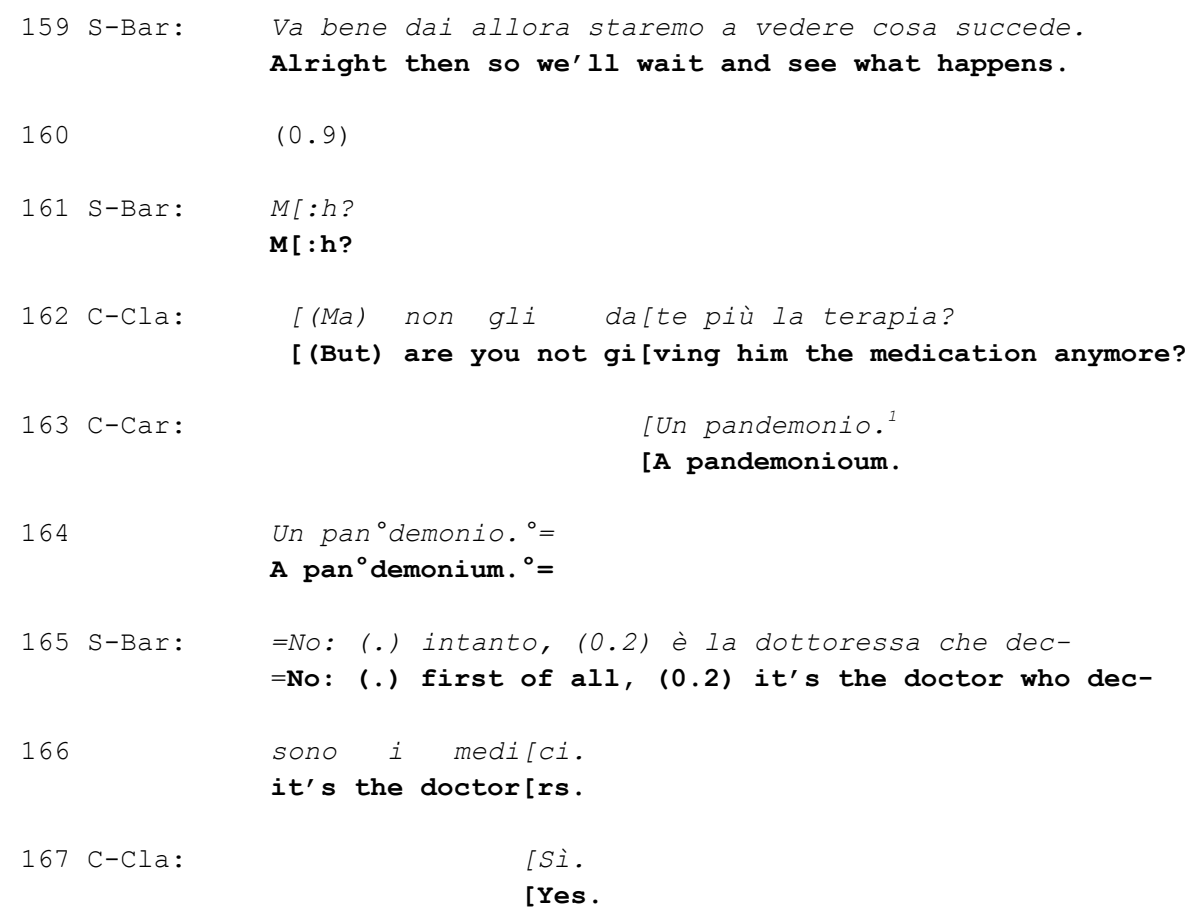

After Barbara makes a move to close the topic of Franco's medication at line 159, Clara asks whether the staff are going to stop giving him the medication (line 162). This suggests that she heard Franco's expression of desire ('I don't want to take the medicines', lines 31-32) as an implicit request to discontinue the medication, and that she treats the staff as having the ability to grant that request. Barbara subsequently corrects Clara's understanding. At lines 165-166, Barbara starts and abandons the 
utterance 'it's the doctor who dec((ides))' where she refers to Franco's doctor (as demonstrated by her use of the feminine Italian noun 'dottoressa') and she replaces it with the more categorical reference to 'the doctors'. With this substitution, Barbara clarifies that the doctors are the professional group entitled to address requests for changes in the clients' pharmacological regime and that the TC staff members are not. She thus re-establishes a socio-relational framework where the staff members cannot be expected to satisfy Franco's desire to stop the medication, ${ }^{2}$ precisely because they do not have that prerogative. This re-constitutes a context where Franco's stated desire cannot be treated as a request. This has important implications for how the TC staff members present themselves in this exchange: it is not they do not want to assist the client; they simply cannot do it.

The analysis of Extract 1 suggests that the staff members and the clients treat a client's assertion of desire as performing an implicit request when (and only when) the assertion targets a good or service that the staff can provide as part of their insititutional remit. The next section examines how the staff members deal with expressions and displays of need and desire that they treat as performing implicit requests.

\section{Treating the $\mathrm{TC}$ clients as lacking entitlement to some good or service}

Whereas the clients' explicit requests target relatively straightforward matters (e.g., authorising a phone call or buying a specific type of cake for a birthday celebration), their implicit requests target things that are arguably more complicated for the staff to provide. In the examples that follow, they involve extending a client's work hours (outside the TC), renewing a long-time expired driver's license, providing Internet access, and buying a car. The clients do not overtly request the staff members' assistance in obtaining these things. Instead, they provide the staff members with opportunities to offer assistance (Curl, 2006) by asserting or displaying that they need, want, or have some interest in those things. ${ }^{3}$

In one case (not examined in this chapter) a staff member (Massimo) treats a client's expressed desire to engage in a group activity as a request, and he eventually grants it. In all the other cases, the staff members respond to the clients' assertions and displays of need and desire by treating the clients as lacking entitlement to the needed/desired goods (on entitlement, see Curl \& Drew, 2008). In this way, they disaffiliate with the clients' project to obtain those goods. In this section, I examine this practice, which is overwhelmingly (although not exclusively) employed by Barbara (the TC educator).

The analysis of the following extracts is organised as follows: for each case, I first examine how the client's turn can be heard as conveying an implicit request. Then, I describe the sequence initiated by the client's turn and focus primarily on the staff 
member's turn that treats the client as lacking entitlement to some needed/desired good (the corresponding lines are arrowed). The clients' implicit requests are conveyed through turns that either claim (extracts 2 and 3) or display (extracts 4 and 5) that the clients want or need something.

Extract 2 illustrates how the staff members deal with a client's implicit request conveyed through an expression of desire.

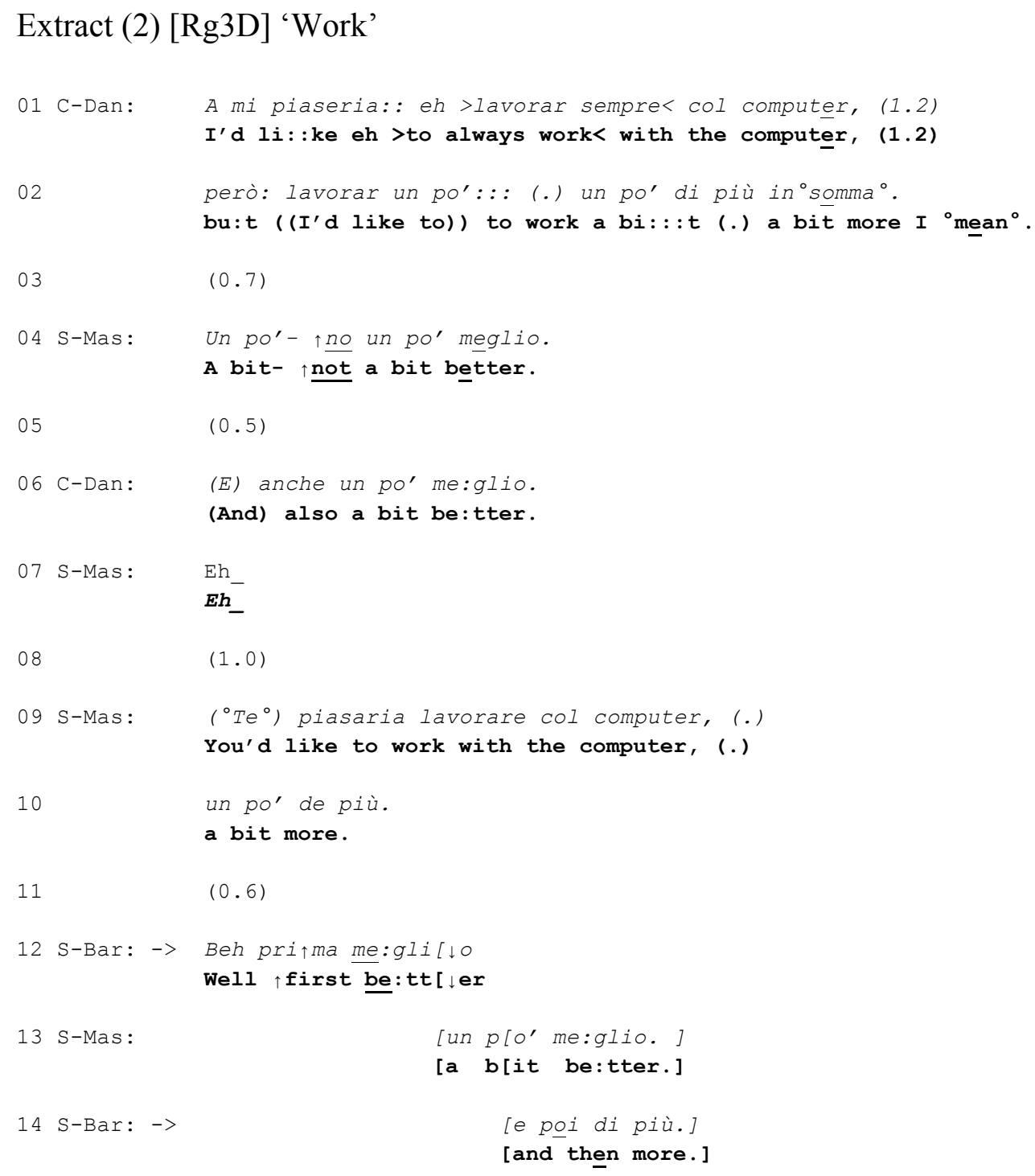

In line 1, Daniele (a client) refers to his part-time secretarial job in a local self-help organisation (this information is available to us from other parts of the recorded meetings); he claims that he would like to carry on doing that job (this is conveyed through the use of 'always'), but that he would like to work more hours ('a bit more') as well. Being designed as an assertion of desire ('I'd like'), this turn can be heard as an implicit request (Couper-Kuhlen, 2014), providing the staff members with an opportunity to offer assistance in the fulfilment of the client's desire. This understanding is supported by the contrastive 'but' in line 2, which singles out something that the client values ('working a bit more'), which is not accessible to him in the present (as opposed to 'working with the computer', which the client is already 
doing). The qualifier 'a bit' in line 2 also supports the understanding of the turn as doing an implicit request, insofar as it minimises the possible burden apportioned on the recipients of the request (Clayman \& Heritage, 2014). In addition to its grammatical design (Couper-Kuhlen, 2014), this turn can be heard as an implicit request against the background of a social relationship where the staff members have the ability to assist the clients in obtaining some goods and services (Clayman \& Heritage, 2014; Stevanovic, 2011) and where they might be willing or expected to do so. In this case, we know that Massimo and Barbara are not Daniele's employers and that, for this reason, they are not in the position of accepting or rejecting a request to work more hours, strictly speaking. Notwithstanding, in their role as support workers, Massimo and Barbara are regularly in contact with the clients' employers (as is suggested in this case by their display of independent knowledge about Daniele's performance at work; see lines 4, 12, and 14). It is in the TC staff members' remit to advocate an increase in Daniele's working hours, or at least to express a favourable opinion when talking to his employer. It is against this socio-relational backdrop that Daniele's turn can be heard as an (implicit) attempt to enlist the staff members' assistance. Although Daniele does not request anything explicitly, his assertion of desire provides the staff members with an opportunity to offer assistance (Curl, 2006).

At line 4, Massimo suggests that Daniele should prioritise the goal to work 'a bit better' over the goal to work more, thereby alluding to Daniele's performance at work as not satisfactory. This utterance can be heard as an interrogative due to the rising intonation on the penultimate syllable of 'meglio.'/'better.', represented here through the underlining (see Rossano, 2010), and as proposing a correction to the client's expression of desire in lines 1-2. At line 6, Daniele accepts Massimo's correction, but he treats it as an addition to a list of goals, thereby refusing to relinquish his stated desire to work more. Relevant for the analysis of Barbara's turn at lines 12 and 14 (the focal turn in my analysis) is that, after an acknowledgement token which may provide for Daniele to elaborate (line 7) and the 1.0 second gap at line 8, Massimo apparently relinquishes the attempt to challenge Daniele's stated desire and acknowledges it through a formulation or summary of the client's position (lines 9-10).

At lines 12 and 14, Barbara, another staff member, resuscitates Massimo's suggestion that Daniele should focus on working better rather than aiming at working more hours. However, unlike Massimo's turn at line 4, Barbara's turn is framed as an assertion, which sharply departs from Daniele's position. Another difference from Massimo's turn is that Barbara treats 'working better' as a necessary precondition for 'working more'. By introducing this precondition, which the client allegedly does not meet (he does not work well enough), the staff member treats him as lacking entitlement, at least temporarily, to the desired outcome of working more hours. In this way, the staff member disaffiliates with (i.e. conveys that she does not endorse or support) the client's project to work more hours. What is the relationship between this action and the request implications of the client's expression of desire? By expressing the desire to work more hours, the client provided the staff with an opportunity to offer 
assistance (although he did not overtly demand it). Now, Barbara does not deny the provision of assistance in any overt manner. However, her claim that the client lacks entitlement looks very much like a reason for not offering assistance (i.e. it would be unreasonable for the staff to support the client in achieving something to which he is not entitled). The non-provision of assistance is strongly implied at lines 12 and 14 where Barbara claims that Daniele should start working better first; any plan to increase his work hours can thus be considered as postponed until this precondition has been met ('first better and then more', lines 12 and 14). At the end of the exchange, assistance has not been formally asked, nor has it been formally denied. At the same time, the client created a context where the staff members could have offered assistance, and one of the staff members (Barbara) made it available that such assistance is not going to be provided.

Before the start of Extract 3, the participants have talked about the renewal of Daniele's driver's license. This discussion occasioned Dina's turn at lines 1-2 where she states the need to gather information about her own expired driver's license.

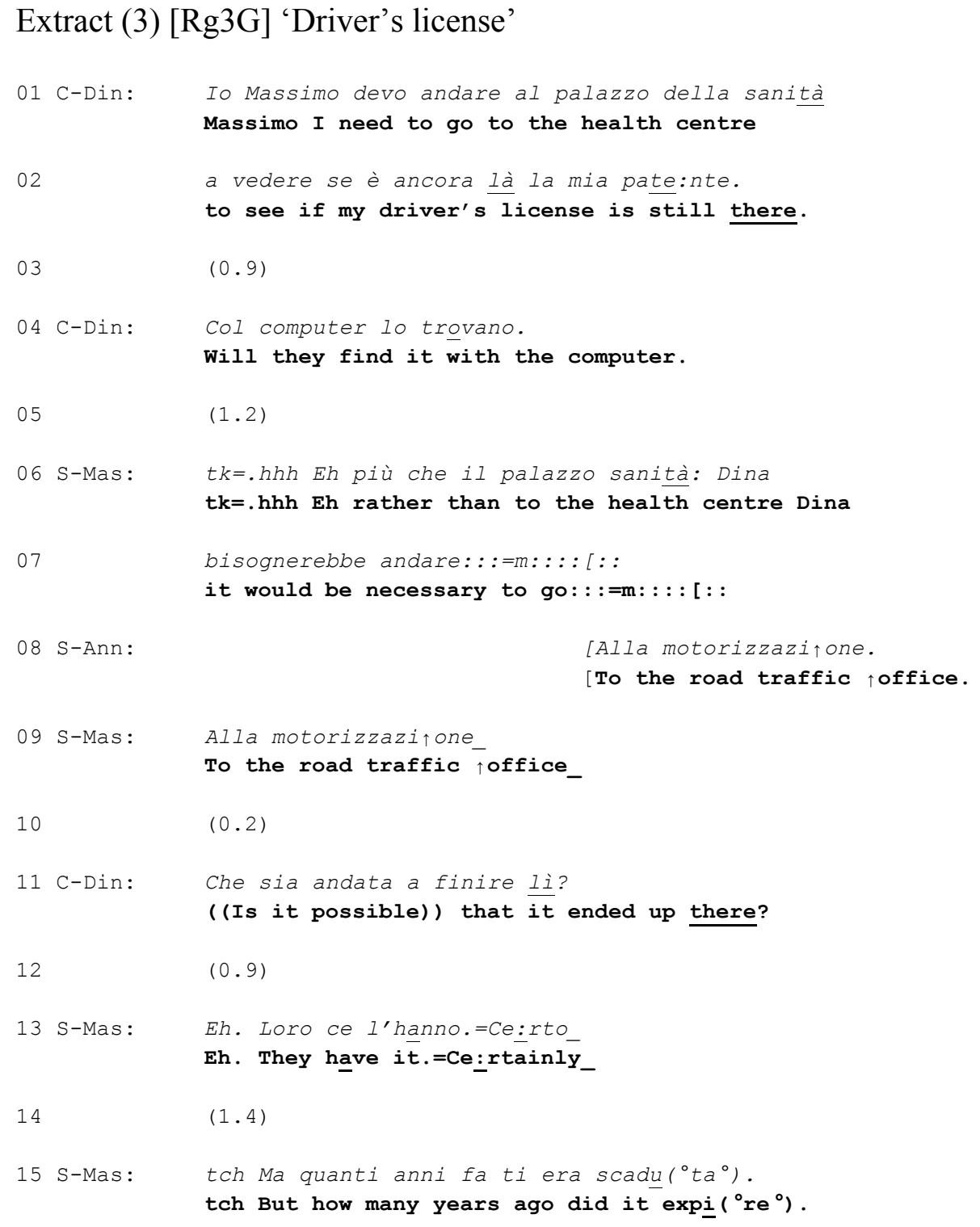




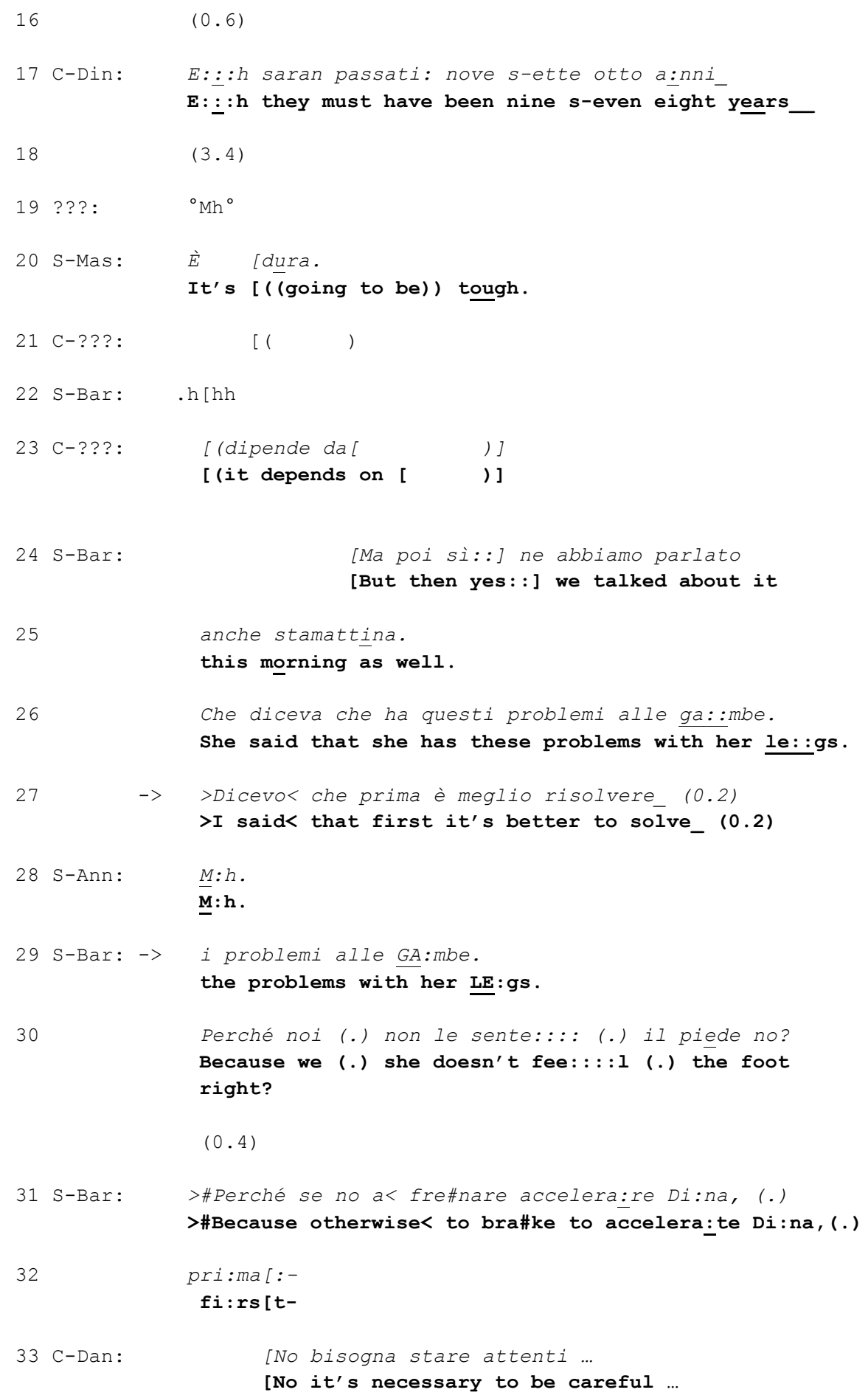

By claiming the need to gather information about her expired driver's license, Dina can be heard as implicitly trying to enlist her nominated recipient ('Massimo', named in line 1) to help in that course of action (Couper-Kuhlen, 2014). In addition to its grammatical design, Dina's turn can be heard as an implicit request against the background of a social relationship where the the staff support the clients with the bureaucratic procedures required to obtain a document (other parts of the recorded meetings indicate that the staff recurrently provide this type of assistance). 
After a gap, at line 4, Dina issues a question about the feasibility of her plan (going to the health centre to inquire about her expired driver's license), which is corrected by the staff at lines 6-9 (she should go to the road traffic office instead). Massimo confirms the correctness of this information at line 13, following a confirmation request by Dina (line 11). After a question about the time elapsed since the expiry of her driver's license (line 15) and Dina's answer at line 17, Massimo negatively assesses the overall feasibility of the plan at line 20 (he seems to suggest that, after all this time, Dina may not be allowed to renew her driver's license). Up to this point, the staff members have introduced reservations about the feasibility of Dina's plan, not about its validity. After some non-discernible words by another client, staff member Barbara addresses the validity of Dina's implicit request (this is the focal turn of my analysis).

Through the turn initial 'But' at line 24, Barbara frames her turn as embodying a disagreeing stance. She then introduces a reservation about Dina's plan to renew her driver's license: she has a health problem (lines 30-31), which would prevent her from driving safely. By claiming that the client lacks this necessary precondition, Barbara treats Dina as lacking entitlement (at least temporarily) to the desired outcome of driving a car. Barbara does not disaffiliate with the client's project as strongly as she does in Extract 2; in Extract 3, Barbara's disaffiliation is somewhat mitigated by her conveyed solicitude for Dina's health. Notwithstanding, Barbara clearly shows that she does not support Dina's project and this can make available to Dina that assistance will not be provided in the achievement of her goal. That assistance will not be provided is strongly implied at line 27, where Barbara suggests that Dina should take care of her health problem first; any plan to gather information about her driver's license is, by implication, postponed until this precondition has been met. As in Extract 2, the client's (alleged) lack of entitlement works as a warrant for not offering assistance (i.e. although Barbara does not deny assistance in any overt manner, her claim that Dina is not fit to drive comes across as a reason for not assisting her in a course of action that could lead her to renew her driver's license). After some further discussion on this matter (data not shown), staff member Massimo suggests that Dina could ask her ex-husband to gather information about her expired driver's license ('Why don't you send Rossi there to see?'). This move provides further evidence that Dina's expression of need was heard as an attempt to enlist someone to assist her and, furthermore, that the staff are not going to provide that assistance.

Before the beginning of Extract 4, staff member Massimo has announced that a new computer room, which will be made available to the clients, has nearly been completed.

Extract (4) [Rg3C] 'Internet'

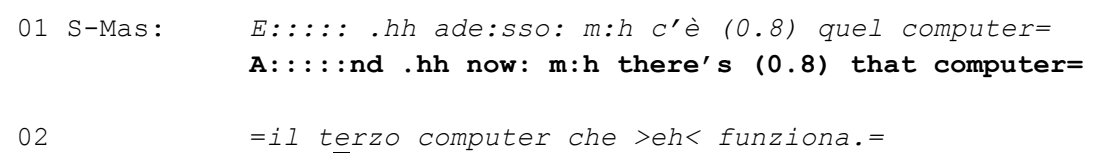


Pino - When assistance is not given

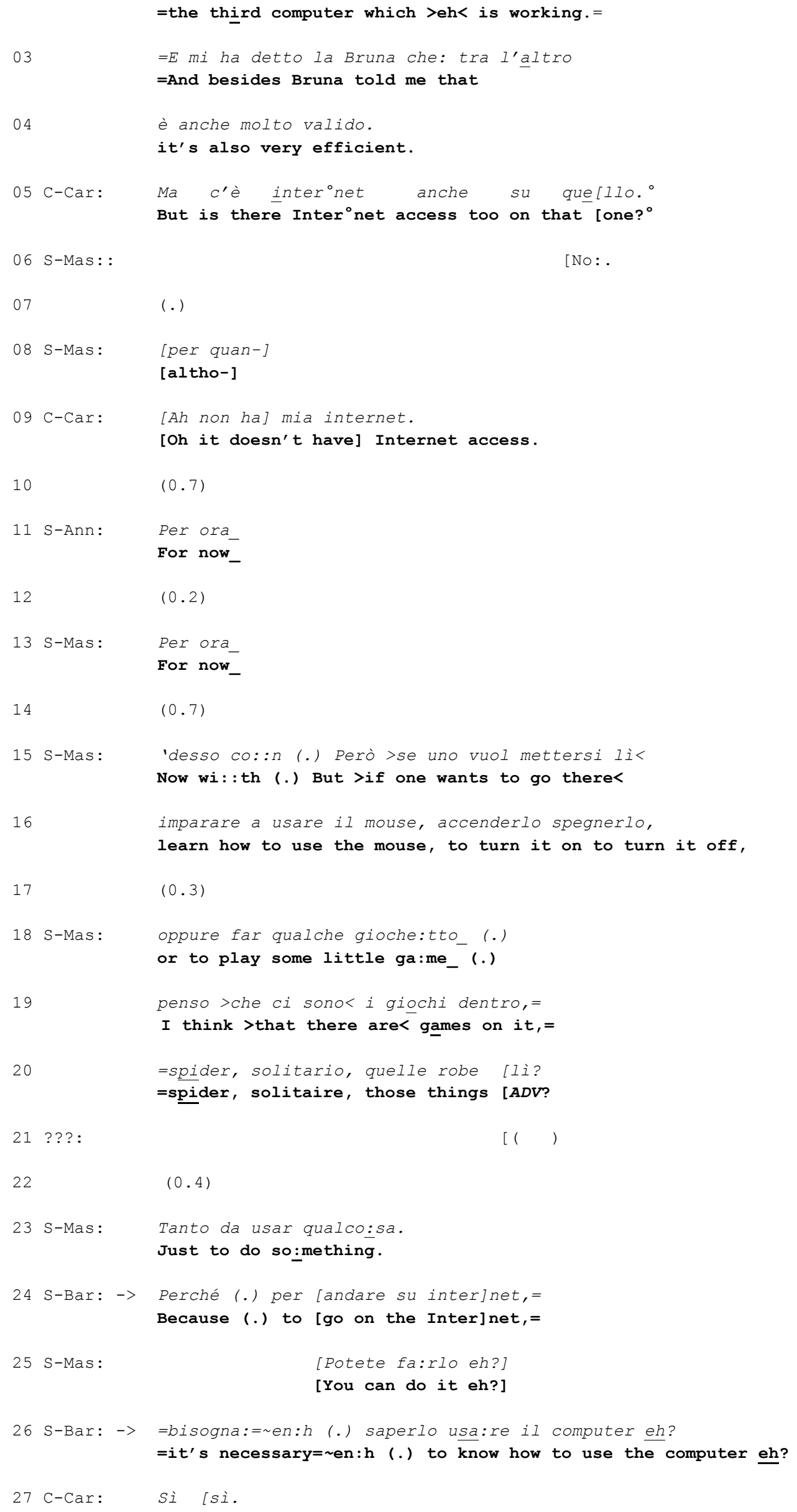


Yes [yes.

28 S-Ann: $\quad[$ Eh si

[Eh yes

At lines 1-4, Massimo singles out one of the computers in the new computer room as particularly 'efficient'. This is followed by a client's question about whether this computer is equipped with Internet access, which possibly displays his interest in having access to the Internet (line 5). Carlo's display of interest (possibly reinforced by his disappointed-sounding receipt of the information that Internet access is not available, at line 9) has request implications, to which the staff members orient at lines 11-13 by implying that Internet access might be provided in the future. At lines 15-23, Massimo seeks to compensate for Carlo's conveyed disappointment by suggesting alternative recreational uses of the computer room (Kendrick \& Drew, 2014). As in the previous cases, the interaction reaches a point where the staff members have introduced reservations (extracts 2 and 3 ) or pointed to barriers (Extract 4 ) to the satisfaction of the client's conveyed desire or need, but they have not contested its intrinsic validity. At lines 24 and 26, Barbara targets the validity of Carlo's conveyed interest in using the Internet.

In this case, Barbara's turn links back to Massimo's previous turn (as suggested by the initial 'Because') and supports the points made therein (lines 13-23). By describing a necessary precondition for using the Internet, which the clients allegedly do not meet (as conveyed through the impersonal construction 'because to go on the Internet it's necessary to know how to use the computer'), Barbara treats the clients (including Carlo) as lacking entitlement to that desirable outcome. This provides a warrant for not making Internet access available (i.e. there is no point providing it if the clients do not know how to operate a computer).

In an exchange preceding the start of Extract 5 (data not shown), Daniele said Eh io son poco autonomo ancora ('Eh I'm still not independent enough'). Staff member Massimo took this to refer to the fact that Daniele does not go to work on his own and that he needs to be taken there by the staff. Massimo encouraged Daniele to start using the bus. This suggests that, for Massimo, using the public transportation is a way of solving Daniele's problem of 'not being independent enough'. In the continuation of the conversation (shown in Extract 5), it becomes apparent that for Daniele 'being more independent' has a different meaning, namely owning a car.

Extract (5) [Rg4E] 'Car'

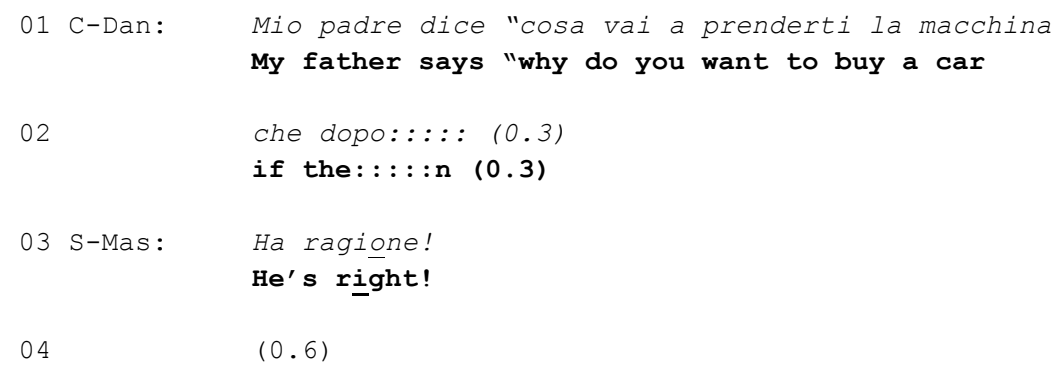


Pino - When assistance is not given

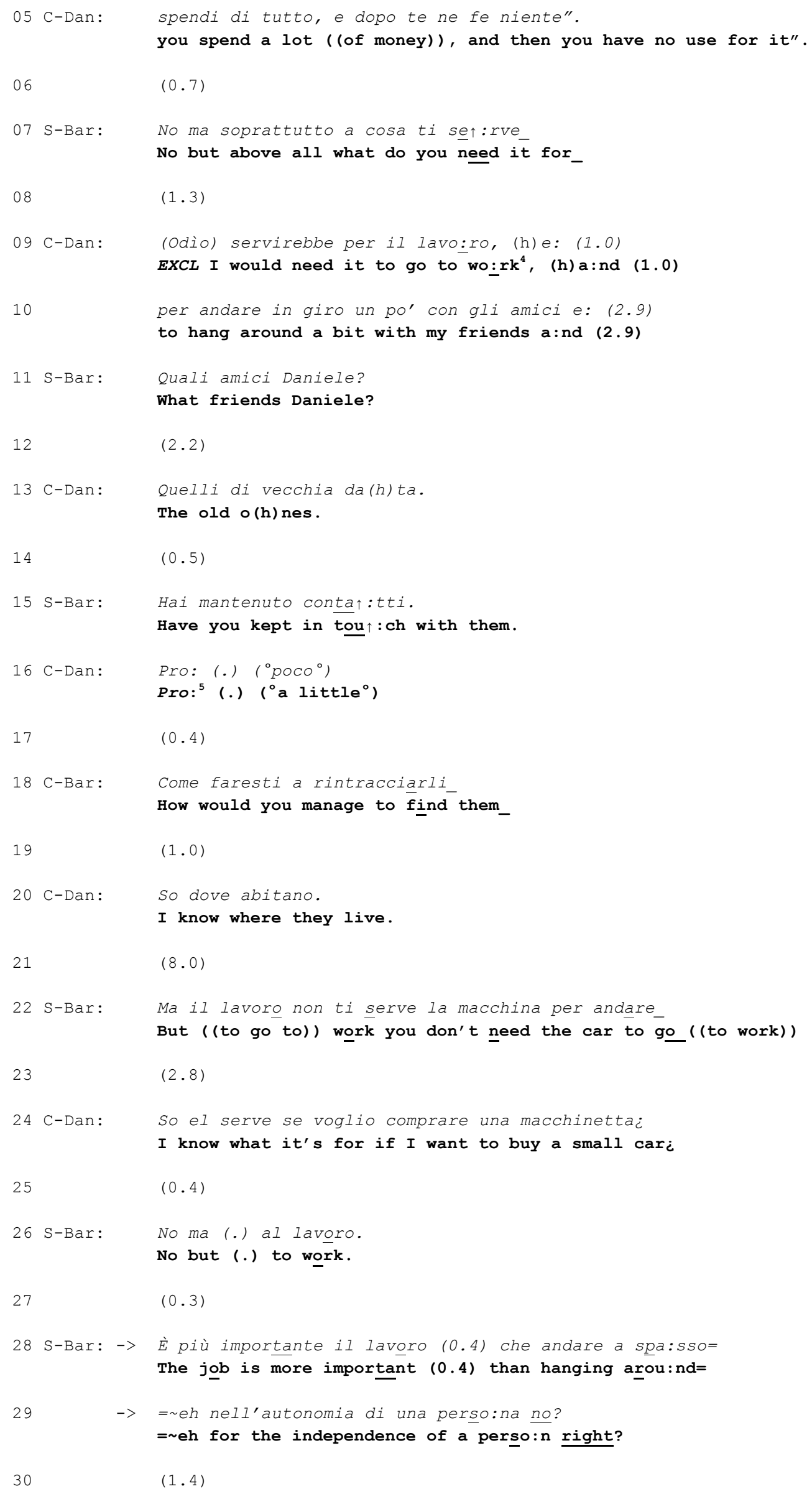




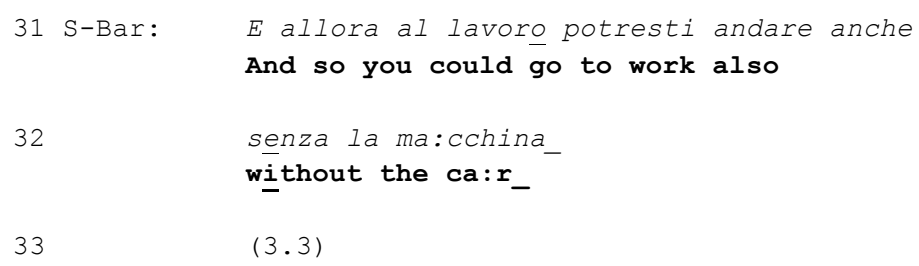

At lines 1-2, Daniele reports that his father disagrees with his project to buy a car. At line 3, Massimo takes a turn before the completion of Daniele's turn to endorse Daniele's father position. Relevant to the focus of this analysis is that Massimo orients to the client's turn at lines 1-2 as displaying a desire or a need for a car. With his turn at line 3, Massimo conveys that he has reservations about Daniele's project to buy a car (although Massimo does not articulate what those reservations are). At line 5, Daniele completes his turn by reporting his father's reasons for disagreeing with his project: the expense would not be justified because Daniele does not need a car. At line 7, Barbara also orients to Daniele's turn as conveying a desire or need to buy a car; she challenges it by inviting the client to support his need for a car, while implying that such reasons may not exist (Koshik, 2003). At lines 9-10, Daniele supports his desire for a car by saying that he could use it to go to work and to hang around with his friends. Across lines 11-18, Barbara challenges Daniele's second argument by implying that he has no friends. However, Daniele resists this challenge by claiming that, although he has not been in touch with his friends a lot (line 16), he could get in touch with them again in the future (line 20). After a gap, at line 22, Barbara changes tack and disagrees with Daniele's first argument (produced at line 9) that he could use the car to go to work. At line 24, Daniele rejects Barbara's overall attempt at dismantling the legitimacy of his stated desire for a car by claiming that he knows what the purpose of having a car is (here Daniele clearly expresses his desire for a car alongside the need for it). However, Barbara refuses to relinquish her line of action (line 26) and claims that having a job is more important than hanging around (lines 28-29) and that Daniele does not need a car to go to work (i.e. she implies that he could use the bus, as Massimo previously suggested; lines 31-32). Here Barbara refers back to Daniele's original complaint (before Extract 5, data not shown) that he is not 'independent' enough and she suggests that, to be independent, Daniele should prioritise working over having a car.

Admittedly, there is a difference between what Barbara does at lines 28-29 of Extract 5 and what she does at the arrowed turns in extracts 2, 3, and 4. In this case, she does not tell the client what he should do before aiming for the desired good or service; she introduces something that is more important and, hence, completely alternative to the client's displayed desire (owning a car). The satisfaction of the client's desire is thus not postponed to an indeterminate future (after a necessary precondition has been met); in this case, the idea that the client needs this particular good (a car) is integrally contested. However, the outcome is very similar: Barbara treats the client as lacking entitlement to the desired outcome (owning a car). Although Barbara does not overtly deny the provision of assistance, this can be inferred from the staff member's overt disaffiliation with the client's expressed need for a car (lines 31-32) (i.e. because she 
disagrees with the idea that the client needs a car, the client can infer that she is not going to assist him in the achievement of that goal).

\section{Discussion}

The clients of the TC display sensitivity to the contingencies involved in granting different goods and services by employing different request formats (Curl \& Drew, 2008). They use explicit request forms (e.g., imperative and interrogative formats) for goods and services that the staff can grant or reject in a relatively straightforward manner. In this chapter, I focused on cases where the clients' requests focus on goods and services that involve more complicated or less immediate granting processes. For instance, in Extract 2, Daniele expresses a desire to work more hours. The staff members cannot directly fulfil his desire (this is the prerogative of his employer); however, they could try to facilitate the process (e.g., by advocating for an increase of his work hours with his employer). In this context, an explicit request would arguably be vulnerable to rejection on the basis that it is not the the staff members' prerogative to make such decisions (as it emerges in Extract 1c in a relation to an implicit request about medication, lines 165-166). By describing his desire to work more hours, the client provides the staff members with an opportunity to offer assistance, but he does not overtly demand it; in this way, he does not risk getting an outright rejection.

The staff members can find themselves in a delicate position in the situations exemplified in this chapter. Because the clients do not produce overt requests for assistance, the staff members are not formally bound to address them (in conversation analytic terms, the non-provision of an offer of assistance following an expression of need or desire is not accountably absent in the way that a missing response to an explicit request is; Curl, 2006). However, in their role as professional helpers, the staff members can be expected to provide assistance when they become aware of the clients' needs and desires. By ignoring the request implications of the clients' conveyed needs and desires, the staff members would be vulnerable to be seen as unwilling to help. At the same time, the staff members may be reluctant to offer assistance when there are doubts about the reasonable character of the clients' conveyed needs and desires (such reservations emerge in extracts 2-5; additionally, the staff members may have further unstated reasons for being reluctant to offer assistance ${ }^{6}$ ). Through the practice examined in this chapter (treating the clients as lacking entitlement to some good or servide and, by way of this, disaffiliating with their projects to obtain those goods/services), the staff members can make available that assistance will not be provided without saying it in so many words. The clients can infer that the staff members will not provide assistance in the achievement of their goals because the staff disaffiliate with (i.e. they show that they do not endorse) the clients' projects to achieve those goals. Furthermore, this practice allows the staff members to avoid being seen as unwilling to help the clients. The clients' alleged lack of entitlement to some good or service works as a warrant for not providing assistance in obtaining that good or service. 
The underlying logic is that it would be unreasonable to assist the clients in achieving things that they are not entitled to obtain. In the sequences analysed in this chapter, then, the clients create opportunities for the staff members to offer assistance, which in turn the staff members do not offer. All of this is handled by the clients and the staff members without overtly requesting assistance or overtly denying it.

\section{Clinical relevance summary}

This study did not address issues of interactional effectiveness (i.e. the potential of an interactional practice to occasion specific outcomes in interaction). Therefore, its results cannot be straightforwardly applied to clinical practice. However, mental health professionals could reflect on how the interactions illustrated in this chapter resonate with their own clinical experience. Do they experience situations where their clients seem to exert pressure for an offer of assistance without making overt requests (Gill, 2005)? How do they usually address such implicit requests? The mental health professionals' responses analysed in this chapter reflect a marked asymmetry whereby the staff members evaluate the clients' needs and desires in terms of their validity. Other professionals could reflect on how their own practices for addressing their clients' requests reflect different types of professional-client relationship and different levels of relational asymmetry. These potential benefits for clinical practice are summarised in Table 34.1.

\section{Summary}

The clients of the TC examined in this study sometimes use expressions of need ('I need X') and desire ('I would like X') to convey implicit requests for assistance. Instead of overtly demanding the staff members' help, the clients thus provide the staff members with opportunities to offer assistance in the achievement of their goals. This can put the TC staff members in a delicate position when, for several reasons, they may be reluctant to assist the clients in the achievement of particular goals (such as renewing a driver's license, buying a car, etc.). The staff members sometimes deal with this problem by disaffiliating with the clients' projects to achieve particular outcomes (e.g., renewing a driver's license) on the basis that the clients (allegedly) lack entitlement to those outcomes. This practice enables the staff members to make available that assistance will not be provided, without saying it in so many words.

\section{Role of funding}

The research leading to these results has received funding from the People Programme (Marie Curie Actions) of the European's Union Seventh Framework Programme 
Pino - When assistance is not given

(FP7/2007-2013) under REA grant agreement no 626893. The contents of this paper reflect only the views of the author and not the views of the European Commission.

\section{Notes}

1 Apparently, this client's verbal production is not connected to the ongoing talk (or at least it does not seem to be treated in that way by the other participants).

2 For reasons explored elsewhere (see Mortari \& Pino, 2014), Barbara's actions convey the assumption that Franco cannot independently decide to stop taking the medication.

3 This is not to claim that the clients always do this intentionally. This study is concerned with the observable effects of the clients' claims and displays of need and desire.

4 This is an attempt at an idiomatic translation but, literally, the client says 'for the job' (in Italian 'lavoro' can mean 'job' or 'work', hence the ambiguity). Given the context of the conversation, it is quite clear that he means that he would be using the car to go to work.

5 This cannot be translated because it is not clear what the client might be going for with the aborted 'Pro:'.

6 For instance, in a continuation of the exchange in Extract 3 (data not shown), Massimo asks Dina 'So you'd still feel up to driving the car' and, following her affirmative answer, he asks 'Are you sure?'. With this, Massimo implies that he has reservations about her ability to drive the car (this could be either because of her mental illness, the medication she is on, or other unstated reasons).

\section{References}

Campling, P. (2001). Therapeutic communities. Advances in Psychiatric Treatment, 7, 365-372.

Clayman, S. E., \& Heritage, J. (2014). Benefactors and beneciaries: Benefactive status and stance in the management of offers and requests. In P. Drew \& E. Couper-Kuhlen (Eds.), Requesting in social interaction (pp. 55-86). Amsterdam: Benjamins.

Couper-Kuhlen, E. (2014). What does grammar tell us about action? Pragmatics, 24, 623-647.

Curl, T. S. (2006). Offers of assistance: Constraints on syntactic design. Journal of Pragmatics, 38, 1257-1280. doi:10.1016/j.pragma.2005.09.004.

Curl, T. S., \& Drew, P. (2008). Contingency and action: A comparison of two forms of requesting. Research on Language \& Social Interaction, 41, 129-153.

Gill, V. T. (2005). Patient 'demand' for medical interventions: Exerting pressure for an offer in a primary care clinic visit. Research on Language \& Social Interaction, 38, 451-479.

Hepburn, A., \& Bolden, G. B. (2013). The conversation analytic approach to transcription. In J. Sidnell \& T. Stivers (Eds.), The Handbook of conversation analysis (pp. 57-76). Boston: Wiley-Blackwell. 
Kendrick, K., \& Drew, P. (2014). The putative preference for offers over requests. In P. Drew \& E. Couper-Kuhlen (Eds.), Requesting in social interaction (pp. 83-110). Amsterdam: Benjamins.

Koshik, I. (2003). Wh-questions used as challenges. Discourse Studies, 5, 51-77.

Mortari, L., \& Pino, M. (2014). Conversational pursuit of medication compliance in a therapeutic community for persons diagnosed with mental disorders. Disability and Rehabilitation, 36, 1419-1430. doi:10.3109/09638288.2013.834987.

Rossano, F. (2010). Questioning and responding in Italian. Journal of Pragmatics, 42, 2756-2771. doi:10.1016/j.pragma.2010.04.010.

Rossi, G. (2012). Bilateral and unilateral requests: The use of imperatives and Mi X? Interrogatives in Italian. Discourse Processes, 49, 426-458. doi:10.1080/0163853X.2012.684136.

Schegloff, E. A. (2007). Sequence organization in interaction: A primer in conversation analysis I. Cambridge: Cambridge University Press.

Sidnell, J., \& Stivers, T. (Eds.). (2013). Handbook of conversation analysis. Boston: Wiley-Blackwell.

Stevanovic, M. (2011). Participants' deontic rights and action formation: The case of declarative requests for action. InLiSt, 52. Retrieved at: www.inlist.uni-bayreuth.de/

Stivers, T. (2008). Stance, alignment, and affiliation during storytelling: When nodding is a token of affiliation. Research on Language \& Social Interaction, 41, 31-57. doi:10.1080/08351810701691123. 